\title{
Toward Preventing Enamel Hypoplasia: Modeling Maternal and Neonatal Biomarkers of Human Calcium Homeostasis
}

\author{
Susan G. Reed ${ }^{a} \quad$ Cameron S. Miller $^{b} \quad$ Carol L. Wagner ${ }^{a} \quad$ Bruce W. Hollis $^{a}$ \\ Andrew B. Lawson ${ }^{b}$ \\ ${ }^{a}$ Department of Pediatrics, Medical University of South Carolina, Charleston, SC, USA; \\ ${ }^{b}$ Department of Public Health Sciences, Medical University of South Carolina, Charleston, SC, USA
}

\section{Keywords}

Early childhood caries - Pregnancy · Deciduous teeth ·

Calcium · Parathyroid hormone $\cdot$ Phosphorus · Vitamin D

\begin{abstract}
Aim: The aim of this study was to assess biomarkers of calcium homeostasis and tooth development, in mothers during pregnancy and their children at birth, for enamel hypoplasia (EH) in the primary maxillary central incisor teeth. Methods: Bayesian methodology was used for secondary data analyses from a randomized, controlled trial of prenatal vitamin $D_{3}$ supplementation in healthy mothers $(N=350)$ and a follow-up study of a subset of the children. The biomarkers were serum calcium $(\mathrm{Ca})$, phosphorus $(\mathrm{P})$, intact parathyroid hormone (iPTH), total circulating 25-dihydroxyvitamin $\mathrm{D}(25(\mathrm{OH}) \mathrm{D})$, and 1,25-dihydroxyvitamin $\mathrm{D}$ $\left(1,25(\mathrm{OH})_{2} \mathrm{D}\right)$. The maternal biomarkers were assayed monthly during pregnancy, and the child's biomarkers were derived from cord blood. Digital images of the child's 2 teeth were scored for EH using Enamel Defects Index criteria for each of the incisal, middle, and cervical regions for an $\mathrm{EH}$
\end{abstract}

extent score. Results: The child EH prevalence was $41 \%$ (60/145), with most defects present in the incisal and middle tooth regions. Cord blood iPTH and $1,25(\mathrm{OH})_{2}$ D levels were significantly associated with EH extent after controlling for maternal factors. For every $1 \mathrm{pg} / \mathrm{mL}$ increase in cord blood iPTH, the EH extent decreased by approximately $6 \%$. For every $10 \mathrm{pg} / \mathrm{mL}$ increase in cord blood $1,25(\mathrm{OH})_{2} \mathrm{D}$, the EH extent increased by almost 30\% (holding all other terms constant and adjusting for subject-level heterogeneity). The relationship between maternal 25(OH)D and maternal mean iPTH varied significantly by EH extent. Conclusion: The results suggest possible modifiable relationships of maternal and neonatal factors of calcium homeostasis during pregnancy and at birth for $\mathrm{EH}$, contributing to the frontier of knowledge regarding sound tooth development for dental caries prevention.

(C) 2019 S. Karger AG, Basel

Oral presentations of earlier versions of this study were made at the 2017 General Session and Exhibition of the International Association for Dental Research, 2017 Oral Epidemiology Forum of the American Association for Dental Research General Session, and a poster presentation at the 2017 Pediatric Academic Societies Meeting.

\section{KARGER}

(c) 2019 S. Karger AG, Basel

E-Mail karger@karger.com

www.karger.com/cre
Susan G. Reed

Department of Pediatrics, Medical University of South Carolina 165 Ashley Avenue

Charleston, SC 29425-9170 (USA)

E-Mail reedsg@musc.edu 


\section{Introduction}

Enamel hypoplasia (EH) is a quantitative defect of dental enamel described as an area of less enamel and with a smooth outline [FDI Commission on Oral Health Research and Epidemiology, 1992; Brook et al., 2001]. EH results from discrete disruptions of enamel matrix secretion during tooth development [Klein, 1931; Kronfeld and Schour, 1939; Giro, 1947]. In contrast to the generalized $\mathrm{EH}$ due to rare inherited disorders such as amelogenesis imperfecta, primary tooth $\mathrm{EH}$ is localized, often linear or pitted, and is acquired via specific and temporal insults during tooth development [Seow, 1991]. Population prevalence rates for nonhereditary $\mathrm{EH}$ in the primary dentition of 2- to 5-year-olds are scarce and vary widely, with reports of $4.2 \%, 22.2 \%, 42.5 \%$, and $99 \%$ from geographic area studies in Brazil, China, Guatemala, and Australia, respectively [Sweeney et al., 1969; Pascoe and Seow, 1994; Li et al., 1995; Correa-Faria et al., 2013]. Primary tooth EH is important because accumulating evidence supports the thesis that primary teeth with $\mathrm{EH}$ are at increased risk for dental caries [Infante and Gillespie, 1977; Nation et al., 1987; Seow et al., 1989; Pascoe and Seow, 1994; Caufield et al., 2012; Seow et al., 2016; Costa et al., 2017], likely due to the presence of undisturbed cariogenic bacteria in the niches of $\mathrm{EH}$ (visible or not to the human eye) and subsequent tooth demineralization [Li et al., 1994].

Two critical questions remain unanswered: (1) what factors during human tooth development contribute to $\mathrm{EH}$, and (2) can these factors be modified? We know that $\mathrm{EH}$ in the primary maxillary central incisor teeth develops mostly in utero. Fetal calcification for crown formation of teeth 51 and 61 begins at about 14 gestational weeks [Sema et al., 2009] and is mostly complete by about 40 gestational weeks [Rushton, 1933]. By an average postnatal age of 1.1 months (range 0.4-1.8), the 51 and 61 tooth crowns are fully formed [Deutsch et al., 1985] and erupt into the oral cavity at approximately 1 year of age. Thus, these 2 teeth provide an enamel record of exposures during pregnancy and at birth that may impact $\mathrm{EH}$ development.

\section{Previous Studies}

There have been few investigations to identify pregnancy and birth factors associated with primary tooth $\mathrm{EH}$. An early review identified maternal and infant nutrition, premature birth, infantile convulsions, and infection as EH risk factors [Giro, 1947]. A 1992 ancillary study of exfoliated primary incisors for hypoplastic pits and grooves from a mother-child study of prenatal lead exposure and congenital anomalies [Needleman et al., 1984] identified a maternal history of smoking, higher prepregnancy weight, and lack of prenatal care during the first trimester as linked to EH. Regarding birth factors, the same study also found significant associations between EH and prematurity including low neonatal birth weight, low Apgar scores, and hypocalcemia [Needleman et al., 1992]. A more recent review supports these findings and adds nutritional deficiencies, especially deficient vitamin $\mathrm{D}$ metabolism, and lack of or compromised mineral absorption to the list of risk factors for primary tooth $\mathrm{EH}$ [Salanitri and Seow, 2013]. A systematic review of prematurity and $\mathrm{EH}$ suggests an increased risk for $\mathrm{EH}$ with prematurity; however, it concludes that additional longitudinal studies are needed [Jacobsen et al., 2014]. The findings from the few studies of EH in low- or very-low-birth weight (VLBW) children are equivocal [Funakoshi et al., 1981; Mellander et al., 1982; Johnsen et al., 1984; Needleman et al., 1992; Nelson et al., 2013]. A twin study from 2011 suggests that environmental or epigenetic factors may exert a greater influence than genetic factors for $\mathrm{EH}$ on the primary maxillary incisor teeth [Taji et al., 2011].

In 1981, the etiology of $\mathrm{EH}$ was hypothesized to be a low serum calcium concentration during enamel formation [Nikiforuk and Fraser, 1981]. Using a "medical-dental study" to identify commonalities between $\mathrm{EH}$ and a range of clinical diseases (vitamin D-dependent rickets, hypoparathyroidism, and pseudohypoparathyroidism), the authors reasoned that a disorder of calcium homeostasis was the "unifying concept" among them [Nikiforuk and Fraser, 1981]. Their hypothesis was extended to include perinatal disturbances of premature birth, gastroenteritis, neonatal tetany, and calcium loss due to acute diarrheal disease [Nikiforuk and Fraser, 1981]. Indeed, there is evidence that $\mathrm{EH}$ is associated with diseases of calcium homeostasis [Klein, 1931; Kronfeld and Schour, 1939; Sarnat and Schour, 1941, 1942; Giro, 1947; Via and Churchill, 1957; Kreshover et al., 1958; Miller and Forrester, 1959; Via and Churchill, 1959; Via et al., 1959; Richards et al., 1967; Cohen and Diner, 1970; Fraser and Nikiforuk, 1982; Needleman et al., 1992]. The key biological components of calcium homeostasis are the hormones 1,25 -dihyroxyvitamin $\mathrm{D}\left(1,25(\mathrm{OH})_{2} \mathrm{D}\right)$ and intact parathyroid hormone (iPTH), as well as the elements calcium $(\mathrm{Ca})$ and phosphorus $(\mathrm{P})$. Importantly, these are also the key biologic components of dental enamel formation [Nikiforuk and Fraser, 1979; Ranggard, 1994; Ranggard et al., 1994, 1995; Woltgens et al., 1995; Hubbard, 2000; Sabel et al., 2009a, 2009b; Merheb et al., 2016; Lacruz et al., 2017].
56

Caries Res 2020;54:55-67 DOI: $10.1159 / 000502793$
Reed/Miller/Wagner/Hollis/Lawson 


\section{Current Study}

To assess this "unifying concept," we focused our study on the human model of mother and child factors during pregnancy through delivery to characterize in utero $\mathrm{EH}$ development in the primary maxillary central incisor teeth (51 and 61). During pregnancy, maternal $\mathrm{Ca}$ and $\mathrm{P}$ are actively transported to the fetus via the placenta, resulting in normal fetal circulating concentrations that are higher than maternal concentrations [Kronfeld et al., 1971; Kovacs, 2015]. While the maternal hormones $1,25(\mathrm{OH})_{2} \mathrm{D}$ and iPTH do not cross the placenta, the precursor for $1,25(\mathrm{OH})_{2} \mathrm{D}$ - i.e., 25 -hydroxyvitamin $\mathrm{D}$ or $25(\mathrm{OH}) \mathrm{D}$ - does cross the placenta [Evans et al., 2004]. In fetal circulation, extrarenal hydroxylation of $25(\mathrm{OH}) \mathrm{D}$ is the predominant source of fetal $1,25(\mathrm{OH})_{2} \mathrm{D}$ (the active form of vitamin $\mathrm{D}$ ) and is subject to relative amounts of 25(OH)D substrate [Cianferotti et al., 2017]. The relatively high fetal circulating $\mathrm{Ca}$ concentrations suppress fetal iPTH. The fetal kidneys are relatively unimportant for mineral control [Kovacs, 2015].

We operationalized the hypothesized "unifying concept" [Nikiforuk and Fraser, 1981] by utilizing biomarkers of calcium homeostasis during primary maxillary tooth development and employed Bayesian methodology to assess relationships among maternal and neonatal factors for their impact on $\mathrm{EH}$ development.

\section{Subjects and Methods}

We conducted secondary analyses of longitudinal data from a randomized, controlled trial (RCT) of maternal prenatal vitamin $\mathrm{D}_{3}$ supplementation and a follow-up study of the children [Hollis et al., 2011; Stukes et al., 2016]. The population included healthy AfricanAmerican, Caucasian, and Hispanic women from the Charleston area (South Carolina) with a singleton pregnancy (2004-2009; $N=$ 350 ). Women with preexisting calcium or parathyroid conditions, alimentary absorption problems, type 1 diabetes, uncontrolled thyroid disease, or chronic diuretic or cardiac medication therapy (including calcium channel blockers) were excluded.

The women were stratified by race/ethnicity and randomly assigned to oral vitamin $\mathrm{D}_{3}$ supplementation of 400 (control group), 2,000, or 4,000 IU/day. Maternal data were collected monthly from pregnancy week 12 through delivery by interviewer-assisted study questionnaires, medical records, and blood and urine samples. Cord blood samples were collected at birth. Dental images were made when the child reached 2 years of age, although some children were older. Of the 194 mother-child pairs having consented to the follow-up study, 161 mother-child pairs had the opportunity for dental imaging and 145 children were imaged. The primary reason for mothers not participating in the follow-up study was lack of available time, and the primary reasons for children not having dental images made were lack of camera availability and/or lack of child cooperation.

Enamel Hypoplasia and Ca Homeostasis during Pregnancy and at Birth

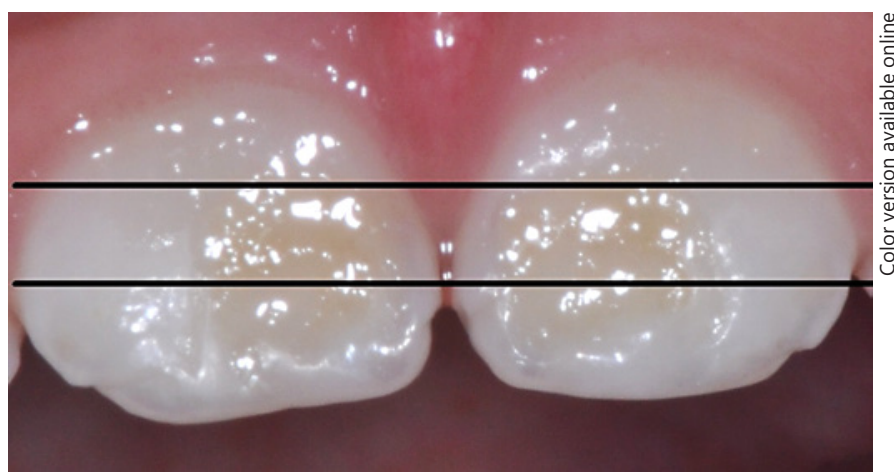

Fig. 1. Scoring of enamel hypoplasia (EH) extent for primary maxillary central incisors. EH extent score $=$ sum of scores for EH by tooth regions. $\mathrm{EH}$ extent scores grouped for $\mathrm{EH}=0, \mathrm{EH}=1$, and $\mathrm{EH}>1$. Example using an image of teeth 51 and 61: tooth 51, cervical $\mathrm{EH}=0$, middle $\mathrm{EH}=1$, incisal $\mathrm{EH}=1$; tooth 61, cervical $\mathrm{EH}=$ 0 , middle $\mathrm{EH}=1$, incisal $\mathrm{EH}=1 . \mathrm{EH}$ extent score $=4$; $\mathrm{EH}$ extent group, EH>1. Modified from Brook et al. [2001] and Elcock et al. [2006].

Covariates of calcium homeostasis from maternal and cord blood were assessed by the MUSC (Medical University of South Carolina) Clinical Chemistry Laboratory for serum Ca and P levels using a standard methodology, and the MUSC Hollis Laboratory measured circulating $1,25(\mathrm{OH})_{2} \mathrm{D}$ and precursor $25(\mathrm{OH}) \mathrm{D}$ levels using a rapid direct radioimmunoassay [Hollis et al., 1993] and iPTH levels by immunoradiometric assay (DiaSorin Corporation, Stillwater, MN, USA).

The primary outcome, $\mathrm{EH}$, was scored for the facial surfaces of teeth 51 and 61 from digital images made with a digital camera (Nikon D90 SLR; Nikon Inc., Melville, NY, USA) fitted with a ring flash and a 105-mm macro lens with settings at f/32 aperture, 1/60 shutter speed, and $3 \times$ magnification. Three nonoverlapping regions (incisal, middle, and cervical) were scored using the Enamel Defects Index (EDI) [Brook et al., 2001]. The scores were summed for the 2 teeth for a child $\mathrm{EH}$ extent score, with possible values of 0-6 (Fig. 1). Intra-examiner reliability was determined at the child level by a comparative rescore of the 6 tooth regions for $15 \%$ of the children $(\kappa=0.779)$. Decayed, restored, and missing teeth or regions (due to dental caries, trauma, or exfoliation) were excluded from this study's analyses.

\section{Methods for Data Analyses}

Maternal age, race/ethnicity, body mass index (BMI), smoking, dietary calcium, infections, reflux, medications, hypertensive disorders of pregnancy, magnesium therapy, preterm labor, and serum $25(\mathrm{OH}) \mathrm{D}, 1,25(\mathrm{OH})_{2} \mathrm{D}, \mathrm{PTH}, \mathrm{Ca}$, and $\mathrm{P}$ values were compared by treatment group (400, 2,000, and 4,000 IU of vitamin $\mathrm{D}_{3} /$ day), by median $25(\mathrm{OH}) \mathrm{D}$, and by median $25(\mathrm{OH}) \mathrm{D}$ status (defined as "deficient" if $<20 \mathrm{ng} / \mathrm{mL}$ [Hollis, 2005; Holick et al., 2011]; "insufficient" if $\geq 20$ but $<32 \mathrm{ng} / \mathrm{mL}$ [Hollis and Wagner, 2004; Hollis, 2005]; "sufficient" if $\geq 32 \mathrm{ng} / \mathrm{mL}$ [Hollis and Wagner, 2004; Hollis, 2005]; and "optimal" if $\geq 40 \mathrm{ng} / \mathrm{mL}$ [Hollis et al., 2011]). Plots were generated for maternal mean $25(\mathrm{OH}) \mathrm{D}, 1,25(\mathrm{OH})_{2} \mathrm{D}, \mathrm{iPTH}, \mathrm{Ca}$, and $\mathrm{P}$ level by gestational week, by treatment group, and by median $25(\mathrm{OH}) \mathrm{D}$ status, 
Table 1. Model coefficients utilizing truncated Poisson regression to model counts of positive EH extent scores

\begin{tabular}{|c|c|c|}
\hline Model term & $\beta$ & $\exp (\beta)$ \\
\hline Maternal median $25(\mathrm{OH}) \mathrm{D}$ status ${ }^{1}$ & $-0.09(-0.68,0.47)$ & $0.91(0.51,1.60)$ \\
\hline Child at birth iPTH & $-0.06(-0.11,-0.01)$ & $0.94(0.90,0.99)$ \\
\hline Child at birth $1,25(\mathrm{OH})_{2} \mathrm{D} / 10$ & $0.25(0.03,0.44)$ & $1.28(1.03,1.55)$ \\
\hline Maternal age & $0.13(-0.35,0.16)$ & $1.14(0.70,1.17)$ \\
\hline $\log ($ maternal BMI $)$ & $-0.53(-1.35,0.16)$ & $0.59(0.26,1.17)$ \\
\hline \multicolumn{3}{|l|}{ Maternal race/ethnicity } \\
\hline Caucasian & $0.06(-0.78,1.21)$ & $1.06(0.46,3.35)$ \\
\hline African American & $0.03(-0.91,1.23)$ & $1.03(0.40,3.42)$ \\
\hline Hispanic & $0.05(-0.81,1.21)$ & $1.05(0.44,3.35)$ \\
\hline
\end{tabular}

EH, enamel hypoplasia; iPTH, intact parathyroid hormone; BMI, body mass index. 1 "Deficient" or "insufficient" median maternal 25(OH)D values are $<32 \mathrm{ng} / \mathrm{mL}$, and "sufficient" or "optimal" values are $\geq 32 \mathrm{ng} / \mathrm{mL}$.

as well as by child EH status, by incisal region, and by EH extent. Maternal reflux medications were grouped by mechanism into antacid (calcium carbonate), $\mathrm{H}_{2}$ blocker, or proton pump inhibitor. Antifungals were further specified as oral fluconazole or topicals.

Bayesian EH Model Building

The modeling process used two approaches with Bayesian frameworks (online suppl. Appendix Supplement A; for all online suppl. material, see www.karger.com/doi/10.1159/000502793). In the first approach, EH was modeled as the outcome and formulated in three ways. Model 1 looked at EH as binary on the child level. Model 2 looked at $\mathrm{EH}$ on the region level for the 2 teeth, using binary data for a single region (incisal, middle, or cervical). Logistic regression was then employed. Model 3 used the EH extent score (Fig. 1). If a region value was missing, the $\mathrm{EH}$ extent score was not calculated, and that child was considered missing $(n=5)$. Using EH extent scores, we conducted truncated Poisson regression with distribution truncated at 7 to prevent invalid scores.

$$
\begin{aligned}
& y_{i}^{s c} \sim \text { TPois }\left(\mu_{i} ; 7\right) \\
& \log \left(\mu_{i}\right)=x_{i}^{t} \beta+R_{i},
\end{aligned}
$$

Model 3

where

$$
\beta \sim N\left(0, \tau_{\beta}^{-1}\right)
$$

and $R_{i}$ consists of chosen random effects for the $i$-th child.

Preliminary analyses assessed associations of covariates with $\mathrm{EH}$ one at a time using two models: one with no other model terms and another with an uncorrelated subject-level random effect. The subject-level random effect was included to ensure that coefficient effects could not be explained solely by unmeasured heterogeneity at the child level. These associations were assessed one at a time because the number of covariates prohibited the use of selection techniques that could incorporate all covariates. We limited the covariates to those with published or plausible associations, as well as those determined a priori as fixed variables for model adjustment (maternal median 25(OH)D status, race/ethnicity, age, and BMI at pregnancy week 12). There were two categories of covariates: (1) longitudinal maternal covariates (iPTH, Ca, P, 25(OH)D,
$1,25(\mathrm{OH})_{2} \mathrm{D}$, and counts of infections) and (2) time-invariant covariates (maternal age and maternal race/ethnicity, as well as cord blood iPTH, Ca, P, $25(\mathrm{OH}) \mathrm{D}$, and $\left.1,25(\mathrm{OH})_{2} \mathrm{D}\right)$. The longitudinal maternal covariates included both continuous and binary covariates. For the continuous longitudinal covariates $(25(\mathrm{OH}) \mathrm{D}, \mathrm{iPTH}$, and $\mathrm{Ca}$ ), summary methods included the mean, median, change in value for multiple time frames, change + baseline, maximum, and maximum + baseline. For the binary longitudinal covariates (indicators of acid reflux and infections at each visit), the data were summarized as either indicators over the course of the study or counts.

After conducting these preliminary analyses, Model 3 (the EH extent score) was used to generate a full model that included covariates with demonstrated associations ( 0.05 level) and those that we had determined (a priori) would require model adjustment to reduce potential confounding. In addition to these covariates, an uncorrelated, subject-level random effect was included to account for unmeasured heterogeneity in the study population.

Using backwards model selection, the covariates with the smallest coefficient magnitudes and the largest 95\% credible intervals (relative to the other coefficients) were removed one at a time. At each stage of selection, the deviance information criterion (DIC) [Spiegelhalter et al., 2014] was calculated. A final model (Table 1, Model 3) was chosen using the DIC as a primary criterion and parsimony as a secondary criterion. To check the validity of this stepwise procedure, we ran a Gibbs variable selection using Markov chain Monte Carlo (MCMC) methods with the full model and centered covariates. The Gibbs variable selection involves the inclusion of entry parameters for each coefficient, where each entry parameter is given a Bernoulli prior distribution and a beta $(1,1)$ hyperprior distribution [O'Hara and Sillanpää, 2009]. Inclusion probabilities were computed as posterior averages of the entry states.

Bayesian Longitudinal Modeling of Maternal 25(OH)D

In the second modeling approach, $25(\mathrm{OH}) \mathrm{D}$ concentrations for gestational weeks $12-36$ were modeled using a linear mixed model:

$$
\begin{aligned}
& y_{i j} \sim N\left(\mu_{i j}, \tau_{y}^{-1}\right) \\
& \mu_{i j}=x_{i j}^{t} \beta+R_{i j},
\end{aligned}
$$

Model 4

where $j$ denotes time for the $i$-th mother. 
Table 2. Maternal demographic, behavioral, birth, and blood chemistry characteristics by maternal treatment group and median $25(\mathrm{OH}) \mathrm{D}$ status, as well as by child $\mathrm{EH}$ status and extent group

\begin{tabular}{|c|c|c|c|c|c|c|}
\hline & \multirow{2}{*}{$\begin{array}{l}\text { All } \\
(n=161)\end{array}$} & \multicolumn{3}{|c|}{ Treatment group } & \multicolumn{2}{|c|}{ Median $25(\mathrm{OH})$ D status ${ }^{\mathrm{d}}$} \\
\hline & & $\begin{array}{l}400 \mathrm{IU} \\
(n=55)\end{array}$ & $\begin{array}{l}2,000 \mathrm{IU} \\
(n=51)\end{array}$ & $\begin{array}{l}4,000 \mathrm{IU} \\
(n=55)\end{array}$ & $\begin{array}{l}\text { deficient or } \\
\text { insufficient } \\
(n=58)\end{array}$ & $\begin{array}{l}\text { sufficient or optimal } \\
(n=103)\end{array}$ \\
\hline \multicolumn{7}{|l|}{ Maternal demographic information } \\
\hline Maternal age, years ${ }^{\mathrm{a}}$ & $27.5(5.6)$ & $27.5(5.8)$ & $28.4(5.4)$ & $26.7(5.4)$ & $24.7(4.9)$ & $29.0(5.3)$ \\
\hline \multicolumn{7}{|l|}{ Race/ethnicity $^{\mathrm{b}}$} \\
\hline Caucasian & $47(29.2)$ & $17(30.9)$ & $12(23.5)$ & $18(32.7)$ & $3(5.2)$ & $44(42.7)$ \\
\hline African-American & $57(35.4)$ & $17(30.9)$ & $20(39.2)$ & $20(36.4)$ & $33(56.9)$ & $24(23.3)$ \\
\hline Hispanic & $57(35.4)$ & $21(38.2)$ & $19(37.3)$ & $17(30.9)$ & $22(37.9)$ & $35(34.0)$ \\
\hline \multicolumn{7}{|l|}{ Smoking status } \\
\hline No & $155(96.3)$ & $53(96.4)$ & $49(96.1)$ & $53(96.4)$ & $55(94.8)$ & $100(97.1)$ \\
\hline Yes & $5(3.1)$ & $2(3.6)$ & $2(3.9)$ & $1(1.8)$ & $3(5.2)$ & $2(1.9)$ \\
\hline NA & $1(0.6)$ & $0(0.0)$ & $0(0.0)$ & $1(1.8)$ & $0(0.0)$ & $1(1.0)$ \\
\hline Height, inches & $62.8(5.2)$ & $64.2(7.5)$ & $61.8(2.9)$ & $62.3(4.0)$ & $63.4(7.3)$ & $62.5(3.8)$ \\
\hline Weight, lbs & $163.6(43.7)$ & $153.9(37.7)$ & $171.1(48.3)$ & $165.3(43.5)$ & $169.9(47.7)$ & $160.3(41.4)$ \\
\hline BMI & $28.6(7.0)$ & $28.0(6.0)$ & $30.0(8.2)$ & $27.8(6.3)$ & $30.2(7.3)$ & $27.8(6.7)$ \\
\hline Antacid count (weeks 12-36) & $1.5(1.9)$ & $1.4(1.9)$ & $1.4(1.8)$ & $1.7(2.1)$ & $1.1(1.6)$ & $1.7(2.1)$ \\
\hline Gestation, weeks & $38.8(2.2)$ & $38.9(2.4)$ & $38.7(2.2)$ & $38.8(2.1)$ & $38.5(2.6)$ & $39.0(1.9)$ \\
\hline \multicolumn{7}{|l|}{ Delivery method } \\
\hline Spontaneous delivery & $108(67.1)$ & $32(58.2)$ & $36(70.6)$ & $40(72.7)$ & $41(70.7)$ & $67(65.0)$ \\
\hline Assisted vaginal & $6(3.7)$ & $1(1.8)$ & $1(2.0)$ & $4(7.3)$ & $1(1.7)$ & $5(4.9)$ \\
\hline C-section after onset of labor & $28(17.4)$ & $14(25.5)$ & $8(15.7)$ & $6(10.9)$ & $10(17.2)$ & $18(17.5)$ \\
\hline C-section with no labor & $19(11.8)$ & $8(14.5)$ & $6(11.8)$ & $5(9.1)$ & $6(10.3)$ & $13(12.6)$ \\
\hline \multicolumn{7}{|l|}{ Maternal blood chemistry values ${ }^{c}$} \\
\hline $25(\mathrm{OH}) \mathrm{D}, \mathrm{ng} / \mathrm{mL}$ & $34.5(14.7)$ & $30.4(13.7)$ & $34.1(13.7)$ & $39.0(15.3)$ & $22.5(9.3)$ & $41.1(12.7)$ \\
\hline $1,25(\mathrm{OH})_{2} \mathrm{D}, \mathrm{pg} / \mathrm{mL}$ & $102.0(40.5)$ & $93.3(33.4)$ & $105.6(43.8)$ & $107.3(42.3)$ & $90.6(32.6)$ & $108.2(43.0)$ \\
\hline iPTH, pg/mL & $18.5(10.5)$ & $18.9(10.8)$ & $18.2(10.5)$ & $18.3(10.3)$ & $21.5(10.9)$ & $16.9(10.0)$ \\
\hline Calcium, mg/dL & $9.0(0.3)$ & $9.0(0.3)$ & $8.9(0.4)$ & $9.0(0.4)$ & $8.9(0.3)$ & $9.0(0.4)$ \\
\hline \multirow[t]{3}{*}{ Phosphorus, mg/dL } & $3.9(0.6)$ & $3.9(0.6)$ & $4.0(0.6)$ & $3.9(0.6)$ & $3.9(0.6)$ & $4.0(0.6)$ \\
\hline & \multirow{2}{*}{$\begin{array}{l}\text { All } \\
(n=161)\end{array}$} & \multicolumn{2}{|c|}{ Child EH status } & \multicolumn{3}{|c|}{ Child EH extent group ${ }^{e}$} \\
\hline & & $\begin{array}{l}\text { no EH } \\
(n=85)\end{array}$ & $\begin{array}{l}\mathrm{EH} \\
(n=60)^{\mathrm{e}}\end{array}$ & $\begin{array}{l}\text { no EH } \\
(n=85)\end{array}$ & $\begin{array}{l}\mathrm{EH}=1 \\
(n=23)\end{array}$ & $\begin{array}{l}\mathrm{EH}>1 \\
(n=32)\end{array}$ \\
\hline \multicolumn{7}{|l|}{ Maternal demographic information } \\
\hline Maternal age, years ${ }^{\mathrm{a}}$ & $27.5(5.6)$ & $27.2(5.4)$ & $28.2(5.7)$ & $27.2(5.4)$ & $28.5(5.8)$ & $28.1(6.0)$ \\
\hline \multicolumn{7}{|l|}{ Race/ethnicity ${ }^{\mathrm{b}}$} \\
\hline Caucasian & $47(29.2)$ & $24(28.2)$ & $22(36.7)$ & $24(28.2)$ & $11(47.8)$ & $11(34.4)$ \\
\hline African-American & $57(35.4)$ & $33(38.8)$ & $18(30.0)$ & $33(38.8)$ & $3(13.0)$ & $13(40.6)$ \\
\hline Hispanic & $57(35.4)$ & $28(32.9)$ & $20(33.3)$ & $28(32.9)$ & $9(39.1)$ & $8(25.0)$ \\
\hline \multicolumn{7}{|l|}{ Smoking status } \\
\hline No & $155(96.3)$ & $81(95.3)$ & $58(96.7)$ & $81(95.3)$ & $23(100.0)$ & $30(93.8)$ \\
\hline Yes & $5(3.1)$ & $4(4.7)$ & $1(1.7)$ & $4(4.7)$ & $0(0.0)$ & $1(3.1)$ \\
\hline NA & $1(0.6)$ & $0(0.0)$ & $1(1.7)$ & $0(0.0)$ & $0(0.0)$ & $1(3.1)$ \\
\hline Height, inches & $62.8(5.2)$ & $62.4(3.0)$ & $64.4(7.8)$ & $62.4(3.0)$ & $65.0(11.4)$ & $64.4(4.4)$ \\
\hline Weight, lbs & $163.6(43.7)$ & $169.7(45.0)$ & $156.8(39.3)$ & $169.7(45.1)$ & $145.0(33.1)$ & $163.4(37.6)$ \\
\hline BMI & $28.6(7.0)$ & $29.4(7.2)$ & $27.4(6.0)$ & $29.4(7.2)$ & $26.2(4.4)$ & $27.5(5.6)$ \\
\hline Antacid count (weeks 12-36) & $1.5(1.9)$ & $1.8(2.2)$ & $1.2(1.6)$ & $1.8(2.2)$ & $1.1(1.9)$ & $1.3(1.5)$ \\
\hline Gestation, weeks & $38.8(2.2)$ & $39.0(1.7)$ & $38.4(2.8)$ & $39.0(1.7)$ & $38.6(2.6)$ & $38.3(3.2)$ \\
\hline \multicolumn{7}{|l|}{ Delivery method } \\
\hline Spontaneous delivery & $108(67.1)$ & $55(64.7)$ & $41(68.3)$ & $55(64.7)$ & $14(60.9)$ & $24(75.0)$ \\
\hline Assisted vaginal & $6(3.7)$ & $2(2.4)$ & $4(6.7)$ & $2(2.4)$ & $2(8.7)$ & $2(6.3)$ \\
\hline C-section after onset of labor & $28(17.4)$ & $13(15.3)$ & $13(21.7)$ & $13(15.3)$ & $5(21.7)$ & $6(18.8)$ \\
\hline C-section with no labor & $19(11.8)$ & $15(17.6)$ & $2(3.3)$ & $15(17.6)$ & $2(8.7)$ & $0(0.0)$ \\
\hline \multicolumn{7}{|l|}{ Maternal blood chemistry values ${ }^{c}$} \\
\hline $25(\mathrm{OH}) \mathrm{D}, \mathrm{ng} / \mathrm{mL}$ & $34.5(14.7)$ & $34.1(14.7)$ & $36.4(14.9)$ & $34.1(14.7)$ & $39.5(14.9)$ & $34.7(14.2)$ \\
\hline $1,25(\mathrm{OH})_{2} \mathrm{D}, \mathrm{pg} / \mathrm{mL}$ & $102.0(40.5)$ & $101.0(40.1)$ & $104.6(41.8)$ & $101.0(40.1)$ & $111.1(49.3)$ & $100.8(35.3)$ \\
\hline $\mathrm{iPTH}, \mathrm{pg} / \mathrm{mL}$ & $18.5(10.5)$ & $17.8(10.7)$ & $19.7(10.9)$ & $17.8(10.7)$ & $18.7(9.0)$ & $20.9(12.2)$ \\
\hline Calcium, mg/dL & $9.0(0.3)$ & $9.0(0.3)$ & $8.9(0.4)$ & $9.0(0.3)$ & $8.9(0.3)$ & $9.0(0.4)$ \\
\hline Phosphorus, mg/dL & $3.9(0.6)$ & $3.9(0.6)$ & $3.9(0.5)$ & $3.9(0.6)$ & $3.9(0.6)$ & $3.9(0.5)$ \\
\hline
\end{tabular}

$\mathrm{EH}$, enamel hypoplasia; $\mathrm{BMI}$, body mass index; $\mathrm{PTH}$, intact parathyroid hormone, ${ }^{\text {a }}$ For continuous variables, the mean is shown with the standard deviation in parentheses. ${ }^{b}$ For categorical variables, the count is displayed with the percentage of the corresponding group in parentheses. ${ }^{\mathrm{c}}$ Maternal blood chemistry values are means for the measure every 4 weeks from week 12 to week 36 of pregnancy. " "Deficient" or "insufficient" median $25(\mathrm{OH}) \mathrm{D}$ values are $<32 \mathrm{ng} / \mathrm{mL}$, and "sufficient" or "optimal" ones are $\geq 32 \mathrm{ng} / \mathrm{mL}$ ${ }^{\mathrm{e}}$ The child EH extent group totals 140 , as 5 children had missing data for a region and were not assigned an extent score. 
Time trends in the $25(\mathrm{OH}) \mathrm{D}$ concentrations were fit to four series using $\mathrm{EH}$ as binary or an extent group, and included or left out a covariate for the $\log (\mathrm{BMI})$. EH extent group was defined as: no $\mathrm{EH}(\mathrm{EH}=0)$, $\mathrm{EH}$ for 1 region $(\mathrm{EH}=1)$, and $\mathrm{EH}$ for more than 1 region $(\mathrm{EH}>1)$. Each series included ten models that accounted for time variations in $25(\mathrm{OH}) \mathrm{D}$ differently. These series started with simple intercept models and added levels of complexity from a random effect common to the $\mathrm{EH}$ categories with a random walk prior (RW), to separate RW terms and the inclusion of iPTH concentrations (online suppl. Appendix Table 6). For each model, differences in EH-specific intercepts or iPTH coefficients were calculated in the MCMC step. A final model was chosen using the DIC.

Model Fitting, Sensitivity, and Prior Specification

For all models evaluated, the model terms were given noninformative priors when possible. Missing covariate values were imputed from an appropriate prior distribution whose parameters were estimated with hyperpriors. Convergence was assessed using trace and density plots, as well as the modified Gelman-Rubin statistic [Brooks and Gelman, 1998]. Before making an inference, converged samples were thinned to reduce autocorrelation. To assess the robustness of our $\mathrm{EH}$ extent definitions, we conducted sensitivity analyses in which observations with a missing EH status or extent score were removed, and model selection and longitudinal modeling were repeated. All data manipulation was performed using $\mathrm{R}$ version 3.2.3, and all models were run using OpenBUGS version 3.2.3 revision 1012 .

\section{Results}

Table 2 presents the maternal demographic, behavioral, and birth characteristics and covariates of calcium homeostasis for gestational weeks $12-36$ by RCT treatment group, median $25(\mathrm{OH}) \mathrm{D}$ status, child $\mathrm{EH}$ status, and child EH extent group. The characteristics of the study population were relatively evenly distributed (except for maternal race/ethnicity) by median $25(\mathrm{OH}) \mathrm{D}$ status and by child EH extent group. Maternal $25(\mathrm{OH}) \mathrm{D}$ and $1,25(\mathrm{OH})_{2} \mathrm{D}$ by treatment group reflected the dose-response bias of the RCT.

The prevalence of $\mathrm{EH}$ among the children was $41 \%$ (60/145). Of the 60 cases with EH, 48\% (29/60) involved only one tooth and $52 \%(31 / 60)$ involved both teeth. When both teeth had $\mathrm{EH}$, the tooth regions impacted were usually parallel (e.g., both incisal, middle, or cervical). Only children with complete data for all six regions $(n=55)$ were assigned an EH extent score ( $n=5$ had missing region values and were considered missing). There were 23 children with an extent score of $\mathrm{EH}=1$, and 32 children with $\mathrm{EH}>1$. The highest observed extent score was 4 . Table 3 presents the child covariates of calcium homeostasis and $\mathrm{EH}$ regions by maternal RCT treatment group, maternal median $25(\mathrm{OH}) \mathrm{D}$ status, child $\mathrm{EH}$ status, and EH extent group.

Figure 2 shows the maternal covariates of calcium homeostasis graphed by gestational week, by child EH status, and by EH extent group. As seen in Figure 2, the trajectory of $\mathrm{Ca}$ and $\mathrm{P}$ changes at 28 weeks, as fetal weight triples and the Ca content quadruples by 40 weeks [Steichen et al., 1980; Bass and Chan, 2006]. Mothers of children without $\mathrm{EH}$ also had consistently higher weekly iPTH concentrations than mothers of children with EH. Online supplementary Appendix Table 1 provides the longitudinal week-level values of maternal covariates for calcium homeostasis by RCT treatment group, median $25(\mathrm{OH}) \mathrm{D}$ status, child $\mathrm{EH}$, and $\mathrm{EH}$ extent. Mothers of children with EH consistently reported lower usage of reflux medications and antacids. Online supplementary Appendix Table 2 displays the longitudinal week-level counts for maternal medication use.

\section{Preliminary Modeling}

Using EH as an extent score (Model 3) produced significant associations with predictors, whereas using $\mathrm{EH}$ as binary by child and by tooth region (Models 1 and 2) did not. Child iPTH and $1,25(\mathrm{OH})_{2} \mathrm{D}$ were significantly associated with EH extent (0.05 level). Because monthly counts with a maternal report of acid reflux displayed a near-significant association, we stratified acid reflux medications and discovered a significant negative association between antacid use (calcium carbonate) and child EH.

\section{Truncated Poisson Regression (Model 3)}

Using the preliminary modeling results, we generated a full model that included main effects for child concentrations of iPTH and $1,25(\mathrm{OH})_{2} \mathrm{D}$ at birth, maternal antacid use during pregnancy, child gestational age, and terms with a priori adjustment (maternal median $25(\mathrm{OH})$ $\mathrm{D}$ status, race/ethnicity, age, and BMI). To capture any potential effect modification in a complex biological system not captured by a univariable model, we added two interactions, one between maternal median $25(\mathrm{OH}) \mathrm{D}$ status and child iPTH and another between maternal median $25(\mathrm{OH}) \mathrm{D}$ status and child $1,25(\mathrm{OH})_{2} \mathrm{D}$. A subjectlevel random effect was in every model.

Model selection proceeded in five stages (online suppl. Appendix Table 3). The last model included significant terms, factors requiring adjustment, and an uncorrelated, subject-level random effect. The change in DIC was $<1$ among all models; therefore, parsimony was used for final model selection. The final model contained main effects 
Table 3. Child cord blood chemistry values and $\mathrm{EH}$ tooth locations by maternal treatment group and maternal median $25(\mathrm{OH}) \mathrm{D}$ status, as well as by child EH status and extent group

\begin{tabular}{|c|c|c|c|c|c|}
\hline \multirow{2}{*}{$\begin{array}{l}\text { All } \\
(n=161)\end{array}$} & \multicolumn{3}{|c|}{ Treatment group } & \multicolumn{2}{|c|}{ Median 25(OH)D status $^{c}$} \\
\hline & $\begin{array}{l}400 \mathrm{IU} \\
(n=55)\end{array}$ & $\begin{array}{l}2,000 \mathrm{IU} \\
(n=51)\end{array}$ & $\begin{array}{l}4,000 \mathrm{IU} \\
(n=55)\end{array}$ & $\begin{array}{l}\text { deficient or } \\
\text { insufficient } \\
(n=58)\end{array}$ & $\begin{array}{l}\text { sufficient or } \\
\text { optimal } \\
(n=103)\end{array}$ \\
\hline
\end{tabular}

\begin{tabular}{|c|c|c|c|c|c|c|}
\hline \multicolumn{7}{|c|}{ Cord blood chemistry values $^{\mathrm{a}}$} \\
\hline $25(\mathrm{OH}) \mathrm{D}, \mathrm{ng} / \mathrm{mL}$ & $22.2(10.5)$ & $17.3(8.9)$ & $21.7(9.6)$ & $27.7(10.4)$ & $14.0(8.6)$ & $26.8(8.6)$ \\
\hline $1,25(\mathrm{OH})_{2} \mathrm{D}, \mathrm{pg} / \mathrm{mL}$ & $37.2(14.9)$ & $31.4(9.6)$ & $39.5(17.9)$ & $40.9(14.3)$ & $32.9(13.4)$ & $39.1(15.3)$ \\
\hline $\mathrm{iPTH}, \mathrm{pg} / \mathrm{mL}$ & $9.8(9.4)$ & $10.2(11.4)$ & $9.9(9.3)$ & $9.3(6.8)$ & $12.2(11.1)$ & $8.5(8.1)$ \\
\hline Calcium, mg/dL & $10.1(0.6)$ & $10.1(0.6)$ & $9.9(0.7)$ & $10.2(0.5)$ & $9.9(0.7)$ & $10.2(0.5)$ \\
\hline Phosphorus, mg/dL & $6.0(1.1)$ & $6.2(1.3)$ & $6.1(1.0)$ & $5.8(1.1)$ & $6.2(1.2)$ & $5.9(1.1)$ \\
\hline \multicolumn{7}{|l|}{ EH regions ${ }^{\mathrm{b}}$} \\
\hline \multicolumn{7}{|l|}{51 tooth } \\
\hline Cervical & $10(6.2)$ & $1(1.8)$ & $6(11.8)$ & $3(5.5)$ & $2(3.4)$ & $8(7.8)$ \\
\hline Middle & $14(8.7)$ & $1(1.8)$ & $6(11.8)$ & $7(12.7)$ & $6(10.3)$ & $8(7.8)$ \\
\hline Incisal & $29(18.0)$ & $10(18.2)$ & $11(21.6)$ & $8(14.55)$ & $11(19.0)$ & $18(17.5)$ \\
\hline \multicolumn{7}{|l|}{61 tooth } \\
\hline Cervical & $10(6.2)$ & $1(1.8)$ & $4(7.8)$ & $5(9.09)$ & $1(1.7)$ & $9(8.7)$ \\
\hline Middle & $15(9.3)$ & $1(1.8)$ & $6(11.8)$ & $8(14.5)$ & $4(6.9)$ & $11(10.7)$ \\
\hline \multirow[t]{3}{*}{ Incisal } & $29(18.0)$ & $12(21.8)$ & $6(11.8)$ & $11(20.0)$ & $(19.0)$ & $18(17.5)$ \\
\hline & \multirow{2}{*}{$\begin{array}{l}\text { All } \\
(n=161)\end{array}$} & \multicolumn{2}{|c|}{ Child EH status } & \multicolumn{3}{|c|}{ Child EH extent group ${ }^{\mathrm{d}}$} \\
\hline & & $\begin{array}{l}\text { no EH } \\
(n=85)\end{array}$ & $\begin{array}{l}\mathrm{EH} \\
(n=60)\end{array}$ & $\begin{array}{l}\text { no EH } \\
(n=85)\end{array}$ & $\begin{array}{l}\mathrm{EH}=1 \\
(n=23)\end{array}$ & $\begin{array}{l}\mathrm{EH}>1 \\
(n=32)\end{array}$ \\
\hline \multicolumn{7}{|c|}{ Cord blood chemistry values ${ }^{a}$} \\
\hline $25(\mathrm{OH}) \mathrm{D}, \mathrm{ng} / \mathrm{mL}$ & $22.2(10.5)$ & $22.6(10.5)$ & $22.7(10.4)$ & $22.6(10.5)$ & $23.4(11.5)$ & $22.9(10.2)$ \\
\hline $1,25(\mathrm{OH})_{2} \mathrm{D}, \mathrm{pg} / \mathrm{mL}$ & $37.2(14.9)$ & $34.5(12.8)$ & $40.6(15.9)$ & $34.5(12.8)$ & $38.5(11.6)$ & $43.1(18.3)$ \\
\hline $\mathrm{iPTH}, \mathrm{pg} / \mathrm{mL}$ & $9.8(9.4)$ & $10.5(9.8)$ & $6.7(5.6)$ & $10.5(9.8)$ & $7.1(6.3)$ & $6.4(5.5)$ \\
\hline Calcium, mg/dL & $10.1(0.6)$ & $10.1(0.6)$ & $10.1(0.7)$ & $10.1(0.6)$ & $10.0(0.4)$ & $10.1(0.8)$ \\
\hline Phosphorus, mg/dL & $6.0(1.1)$ & $6.1(1.1)$ & $5.8(1.3)$ & $6.1(1.1)$ & $5.9(1.1)$ & $5.7(1.4)$ \\
\hline \multicolumn{7}{|l|}{ EH regions ${ }^{\mathrm{b}}$} \\
\hline 51 tooth & & & & & & \\
\hline Cervical & $10(6.2)$ & $0(0.0)$ & $10(16.7)$ & $0(0.0)$ & $1(4.3)$ & $8(25.0)$ \\
\hline Middle & $14(8.7)$ & $0(0.0)$ & $14(23.3)$ & $0(0.0)$ & $2(8.7)$ & $11(34.4)$ \\
\hline Incisal & $29(18.0)$ & $0(0.0)$ & $29(48.3)$ & $0(0.0)$ & $8(34.8)$ & $19(59.4)$ \\
\hline 61 tooth & & & & & & \\
\hline Cervical & $10(6.2)$ & $0(0.0)$ & $10(16.7)$ & $0(0.0)$ & $2(8.7)$ & 7 (21.9) \\
\hline Middle & $15(9.3)$ & $0(0.0)$ & $15(25.0)$ & $0(0.0)$ & $3(13.0)$ & $12(37.5)$ \\
\hline Incisal & $29(18.0)$ & $0(0.0)$ & $29(48.3)$ & $0(0.0)$ & $7(30.4)$ & $20(62.5)$ \\
\hline
\end{tabular}

EH, enamel hypoplasia; iPTH, intact parathyroid hormone. ${ }^{\text {a }}$ For continuous variables, the mean is shown with the standard deviation in parentheses. ${ }^{b}$ For categorical variables, the count is displayed with the percentage of the corresponding group in parentheses. c "Deficient" or "insufficient" median $25(\mathrm{OH})$ D values are $<32 \mathrm{ng} / \mathrm{mL}$, and "sufficient" or "optimal" ones are $\geq 32 \mathrm{ng} / \mathrm{mL}$. $\mathrm{d}$ The child EH extent group totals 140, because 5 children had missing data for a region and were not assigned an extent score.

for child iPTH, child $1,25(\mathrm{OH})_{2} \mathrm{D}$, and terms requiring adjustment (Table 1). The results were similar when median $25(\mathrm{OH}) \mathrm{D}$ was used as a continuous variable (online suppl. Appendix Table 5). Furthermore, when Gibbs variable selection was used (instead of the stepwise pro- cedure), the same final model was produced with main effects for child iPTH and child $1,25(\mathrm{OH})_{2} \mathrm{D}$.

The results indicated a statistically significant, negative association between EH extent and child cord blood iPTH concentration. Specifically, for every $1 \mathrm{pg} / \mathrm{mL}$ in- 


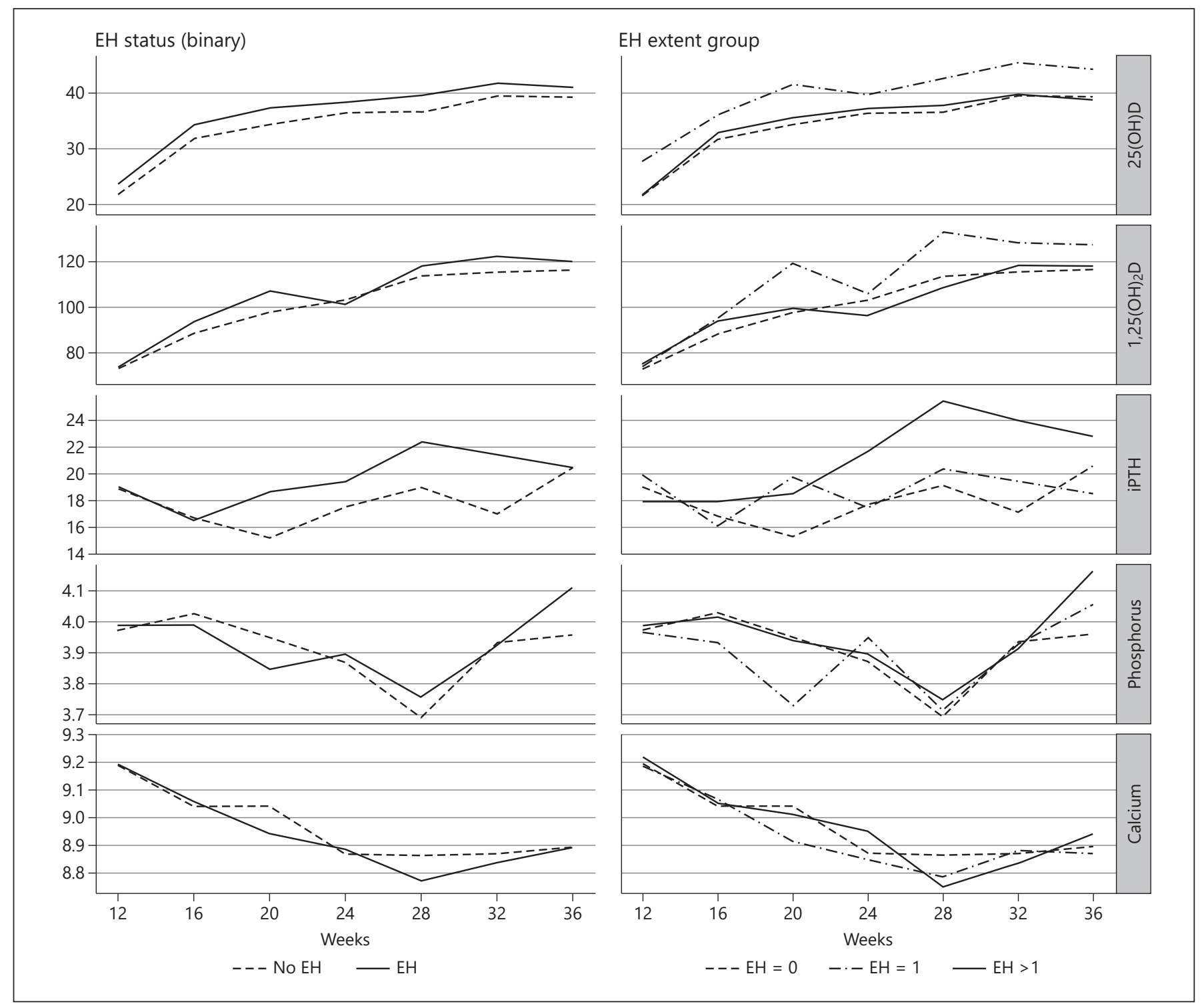

Fig. 2. Maternal blood chemistry values during weeks $12-36$ of pregnancy by child EH score. Units are: $25(\mathrm{OH})$ $\mathrm{D}, \mathrm{ng} / \mathrm{mL} ; 1,25(\mathrm{OH})_{2} \mathrm{D}, \mathrm{pg} / \mathrm{mL}$; iPTH, pg/mL; phosphorus, $\mathrm{mg} / \mathrm{dL}$; calcium, mg/dL. EH, enamel hypoplasia; iPTH, intact parathyroid hormone.

crease in cord blood iPTH (range 0.9-46.7 pg/mL), the expected number of regions scored $\mathrm{EH}$ positive decreased by approximately $6 \%$ (holding all else constant and given an underlying propensity for children to be scored $\mathrm{EH}$ positive). EH extent and cord blood $1,25(\mathrm{OH})_{2} \mathrm{D}$ concentrations also exhibited a statistically significant relationship in the opposite direction. For every $10 \mathrm{pg} / \mathrm{mL}$ increase in cord blood $1,25(\mathrm{OH})_{2} \mathrm{D}$ (range $9.2-100.1 \mathrm{pg} / \mathrm{mL}$ ), the expected number of regions scored positive for EH increased by almost $30 \%$ (holding all other terms constant and adjusting for subject-level heterogeneity).

\section{Bayesian Longitudinal Modeling of 25(OH)D \\ (Model 4)}

We tested whether maternal $25(\mathrm{OH}) \mathrm{D}$ trajectories differed by EH status using our second modeling approach and longitudinal measurements for maternal $25(\mathrm{OH}) \mathrm{D}$. 
When EH was binary, the DIC-selected model used a common time RW and covariate for maternal mean iPTH across weeks 12-36, regardless of BMI adjustment. When $\mathrm{EH}$ was an extent group, the DIC selected a model with a common time RW, a covariate for maternal mean iPTH, and a separate coefficient estimated for the $\mathrm{EH}$ extent group, regardless of BMI adjustment. Overall, the best fit was the model with EH status as extent with a common time RW and separate maternal mean iPTH coefficients (Table 4, online suppl. Appendix Table 6).

The resulting estimated model parameters indicated that the relationship between maternal 25(OH)D and maternal mean iPTH concentrations varied by $\mathrm{EH}$ extent, after adjusting for temporal changes in $25(\mathrm{OH}) \mathrm{D}$ concentrations. We found statistically significant associations for the $\mathrm{EH}=0$ and $\mathrm{EH}>1$ groups that did not differ from each other but that did differ from the $\mathrm{EH}=1$ group association (slightly positive but nonsignificant). For every $1 \mathrm{pg} / \mathrm{mL}$ increase in maternal mean $\mathrm{iPTH}$, the $25(\mathrm{OH}) \mathrm{D}$ concentration for each month decreased by $0.53 \mathrm{ng} / \mathrm{mL}$ (95\% CI: $-0.67,-0.39$ ) for mothers of $\mathrm{EH}=0$ children, and by $0.68 \mathrm{ng} / \mathrm{mL}(95 \% \mathrm{CI}:-0.86,-0.50)$ for mothers of $\mathrm{EH}>1$ children. The sensitivity analyses did not produce substantially different models, parameter estimates, or inferences.

\section{Discussion}

Building on the 1981 hypothesis that disorders of calcium homeostasis provide a "unifying concept" for $\mathrm{EH}$ etiology [Nikiforuk and Fraser, 1981], we conducted Bayesian analyses to illuminate relationships among maternal and neonatal biomarkers of calcium homeostasis during pregnancy and at birth for the development of $\mathrm{EH}$. This is a first prospective study with longitudinal data reflecting healthy mothers and their children with data pertinent to the in utero development of the primary maxillary central incisor teeth. Statistically significant results showed that the relationship between maternal $25(\mathrm{OH}) \mathrm{D}$ and iPTH during pregnancy varied by the extent of child $\mathrm{EH}$, and that neonatal $1,25(\mathrm{OH})_{2} \mathrm{D}$ was positively and iPTH was inversely related to EH extent. This study also introduces an outcome measure of EH extent.

\section{EH and EH Extent Score}

Our relatively healthy population had a child EH prevalence of $41 \%$. This seemingly higher rate is likely due in part to the anticipated higher detection (approx. 2.5 times) when scoring $\mathrm{EH}$ from a digital image, as com-

Enamel Hypoplasia and Ca Homeostasis during Pregnancy and at Birth
Table 4. Final model chosen by DIC using longitudinal 25(OH)D as the outcome

\begin{tabular}{|c|c|c|}
\hline Model term & Mean & $95 \%$ CI \\
\hline \multicolumn{3}{|c|}{ Intercept common to $\mathrm{EH}$ extent } \\
\hline \multicolumn{3}{|c|}{ EH extent-specific intercepts } \\
\hline No EH & 29.30 & $13.03,41.83$ \\
\hline $\mathrm{EH}=1$ & 22.33 & $4.40,35.81$ \\
\hline $\mathrm{EH}>1$ & 34.91 & $17.94,47.73$ \\
\hline \multicolumn{3}{|c|}{ Differences in EH extent-specific intercepts } \\
\hline No EH $-\mathrm{EH}=1$ & 6.97 & $0.36,13.90$ \\
\hline No EH - EH>1 & -5.61 & $-10.71,-0.18$ \\
\hline $\mathrm{EH}=1-\mathrm{EH}>1$ & -12.58 & $-20.12,-4.79$ \\
\hline \multicolumn{3}{|c|}{ Common time random walk } \\
\hline 12 weeks & 1.60 & $-10.41,17.29$ \\
\hline 16 weeks & 10.55 & $-1.64,27.18$ \\
\hline 20 weeks & 13.56 & $1.51,29.90$ \\
\hline 24 weeks & 15.43 & $3.29,31.85$ \\
\hline 28 weeks & 16.57 & $4.33,32.73$ \\
\hline 32 weeks & 18.88 & $6.62,35.45$ \\
\hline 36 weeks & 17.93 & $5.81,33.98$ \\
\hline \multicolumn{3}{|c|}{ EH extent-specific mean iPTH coefficients } \\
\hline No EH & -0.53 & $-0.67,-0.39$ \\
\hline $\mathrm{EH}=1$ & 0.18 & $-0.11,0.49$ \\
\hline $\mathrm{EH}>1$ & -0.68 & $-0.86,-0.50$ \\
\hline \multicolumn{3}{|c|}{ Differences in extent-specific mean iPTH coefficients } \\
\hline No EH $-\mathrm{EH}=1$ & -0.71 & $-1.05,-0.39$ \\
\hline No EH - EH>1 & 0.15 & $-0.08,0.38$ \\
\hline $\mathrm{EH}=1-\mathrm{EH}>1$ & 0.86 & $0.51,1.21$ \\
\hline
\end{tabular}

The mean and 95\% credible interval (CI) for all model components are shown, including those testing the differences in $\mathrm{EH}$ extent-specific intercepts and mean iPTH coefficients. EH, enamel hypoplasia; iPTH, intact parathyroid hormone.

pared to a clinical examination [Seow, 1991; Needleman et al., 1992; Chen et al., 2013]. Also, we used the EDI case definition as any area of "reduced thickness" [Brook et al., 2001] in the frontal or coronal (facial-lingual) plane. Tooth regions that appeared rough due to less enamel or pitted enamel were scored as EH.

In general, we scored $\mathrm{EH}$ in a manner that would likely underestimate, rather than overestimate, the EH prevalence. We classified "questionable $\mathrm{EH}$ " as $\mathrm{EH}=0$, and we scored only facial surfaces of teeth 51 and 61 (vs. all surfaces of a complete primary dentition). Also, we excluded from the analyses any decayed, restored, or missing teeth due to dental caries. The data best fit the model constructed with an $\mathrm{EH}$ extent score for each child that assumed that the extent of the $\mathrm{EH}$ would reflect the amount and/or duration of the insult factor(s) during tooth development (Fig. 1). 
Key Components of Pregnancy and Birth Calcium

Homeostasis and Tooth Development

The results showed that the relationship between maternal $25(\mathrm{OH}) \mathrm{D}$ and mean iPTH concentrations during pregnancy varied significantly by EH extent. These findings may reflect the recent concept of a functional vitamin D deficiency [Hemmingway et al., 2018]. Rather than the independent values of vitamin D and PTH, the impact of the interaction between $25(\mathrm{OH}) \mathrm{D}$ and iPTH reflects a calcium metabolic stress [Hemmingway et al., 2018]. This is a first study to throw light on these relationships of maternal 25(OH)D and iPTH to EH extent.

We found a new and statistically significant and positive relationship between neonatal $1,25(\mathrm{OH})_{2} \mathrm{D}$ concentrations and $\mathrm{EH}$ extent. For every $10 \mathrm{pg} / \mathrm{mL}$ increase in cord blood $1,25(\mathrm{OH})_{2} \mathrm{D}$, the expected number of regions scored positive for $\mathrm{EH}$ increased by almost $30 \%$. We acknowledge that the model estimates were low; however, the results may suggest the need to recruit calcium. The overall circulating $1,25(\mathrm{OH})_{2} \mathrm{D}$ values at birth ranged from 9.2 to $100.1 \mathrm{pg} / \mathrm{mL} .1,25(\mathrm{OH})_{2} \mathrm{D}$ is the active form of vitamin $\mathrm{D}$ and helps regulate amelogenin expression [Papagerakis et al., 1999] for most enamel matrix proteins. These proteins, in turn, play a central role in enamel mineralization as they are replaced by $\mathrm{Ca}$ and $\mathrm{P}$ [Bansal et al., 2012]. We also found that mothers who had more frequently used calcium antacids during pregnancy had children with less extensive $\mathrm{EH}$, although this factor did not remain in our final model for EH extent. More studies are needed to completely characterize the relationship between $1,25(\mathrm{OH})_{2} \mathrm{D}, \mathrm{Ca}$, and $\mathrm{EH}$ development.

Another new finding was that neonatal iPTH concentrations at birth were inversely related to $\mathrm{EH}$ extent. Fetal iPTH is normally suppressed by relatively high circulating Ca concentrations from the mother, and the fetal kidneys are relatively unimportant for mineral control [Kovacs, 2015]. As expected, neonatal $\mathrm{Ca}$ and $\mathrm{P}$ concentrations were similar yet higher than maternal concentrations during pregnancy, and neonatal iPTH concentrations were lower. However, the EH group had even lower birth $\mathrm{iPTH}$ concentrations than the $\mathrm{EH}=0$ group. Although the model estimates were low (i.e., for every $1 \mathrm{pg} / \mathrm{mL}$ increase in cord blood $\mathrm{PTH}$, the expected number of $\mathrm{EH}-$ positive regions decreased by approx. $6 \%$ ), there was also a wide range of neonatal iPTH values $(0.9-46.7 \mathrm{pg} / \mathrm{mL})$.

We also examined $\mathrm{P}$ concentrations as a key component of calcium homeostasis and EH. A recent nested case-control study of preterm VLBW infants found an inverse relationship of $\mathrm{P}$ to $\mathrm{EH}$ [Merheb et al., 2016]. Born at about 28 gestational weeks, VLBW infants with $\mathrm{EH}$ had lower mean P than VLBW infants without EH (5.8 \pm 0.6 vs. $6.4 \pm 0.8 \mathrm{mg} / \mathrm{dL}$ ) [Merheb et al., 2016]. Our study supported this inverse relationship, finding that infants born at $38.8 \pm 2.2$ weeks with lower mean cord blood $\mathrm{P}$ had EH, while those with higher P did not (mean P $5.8 \pm 1.3$ vs. $6.1 \pm 1.1 \mathrm{mg} / \mathrm{dL}$ ). Interestingly, our study also found that maternal $P$ concentrations were lowest at about 28 weeks (Fig. 2), which corresponds to the birth time of the VLBW infants in the prior study. However, neither cord blood P nor maternal $\mathrm{P}$ during pregnancy remained in our models for $\mathrm{EH}$.

\section{Strengths and Limitations of This Study}

A major strength of our study is that our data allowed us to operationalize biological factors associated with maternal and neonatal calcium homeostasis from pregnancy through delivery in a healthy population [Hollis et al., 2011; Stukes et al., 2016; Reed et al., 2017]. Our study accounted for many of the previously identified EH risk factors such as maternal weight (as BMI), smoking, lack of prenatal care, infections, medications, preterm delivery, neonatal birth weight, and Apgar score [Giro, 1947; Needleman et al., 1992]. That said, a potential limitation is the design of the intervention study that collected the source data. To address the potential impacts, we assessed the relationship between $\mathrm{EH}$ and vitamin $\mathrm{D}_{3}$ by maternal treatment group assignments for supplementation, and by serum circulating $25(\mathrm{OH}) \mathrm{D}$ and $1,25(\mathrm{OH})_{2} \mathrm{D}$ concentrations (Tables 2, 3). Maternal vitamin $\mathrm{D}_{3}$ supplementation during pregnancy did not appear to have impacted child $\mathrm{EH}$ when analyzed by maternal treatment group, median $25(\mathrm{OH}) \mathrm{D}$ status, or mean $25(\mathrm{OH}) \mathrm{D}$ during pregnancy. This finding supports an increasing body of literature on the relative safety of vitamin $\mathrm{D}_{3}$ supplementation during pregnancy [Hollis et al., 2011; Wagner et al., 2013] .

Our study population consisted of healthy mothers and their children who participated in a vitamin $\mathrm{D}_{3}$ supplementation study, and those factors would limit the generalizability of our results to populations beyond the original clinic's geographic reach. A relatively small sample size was available for our secondary analysis due to missing data because child $\mathrm{EH}$ was not the focus of the RCT. We addressed this problem of missing data by using Bayesian methodology; however, additional studies on larger, more geographically diverse samples are necessary to validate these results. Finally, our study focused on the maternal and neonatal factors from pregnancy through birth, and we did not include factors of early infancy that may impact EH in the primary maxillary central incisor teeth. 


\section{Conclusion}

The approach and results of this study contribute to the frontier of knowledge regarding sound tooth development for dental caries prevention. Our results suggest possible modifiable relationships amongst maternal and neonatal factors of calcium homeostasis during pregnancy and at birth for EH. Additional longitudinal studies specifically designed with a central focus on factors during pregnancy, at birth, and in early infancy that impact $\mathrm{EH}$ development are needed to validate these findings.

\section{Acknowledgements}

This study involved secondary data analyses of existing resources and received support from NIH Grant R03 DE025082. Data resource support was from NIH Grants R01 HD043921, T35 DE007337, T32 DE017551, P20 RR017696, P20 RR01070, P30 GM103331, L1TR000062, and UL1 TR001450, the Thrasher Research Fund, an AADR Student Research Fellowship, and the South Carolina Clinical and Translational Research (SCTR) Institute with an academic home at MUSC, NIH/NCRR Grant No. UL1 RR029882.

The authors thank the women and children who participated in this study, without whose participation this study would not have been possible; the dedicated study coordinator team consisting of Judy Shary, M.S., Pamela G. Smith, R.N., Martha Murphy, B.S., Betty Bivens, R.A., and Deanna Fanning, R.N., who made the study possible; and the dental imaging team including Lisa Summerlin, R.D.H., MUSC James B. Edwards College of Dental Medicine pre-doctoral student Jeanette Wingate (currently Dr. Wingate), and George Washington University summer internship un- dergraduate student Mallika Murali (currently Dr. Murali). Katharine $\mathrm{H}$. Hendrix, $\mathrm{PhD}$, assisted with manuscript preparation. Dr. Hollis had previous support from DiaSorin Inc. for serving as an academic consultant.

\section{Statement of Ethics}

The study protocols with written, informed consent for the mothers and on behalf of the children were approved by the MUSC Institutional Review Board \#10727 and \#19641 (investigator FDA IND \#66346, ClinicalTrials.gov \#NCT00292591).

\section{Disclosure Statement}

The authors declare no potential or actual conflicts of interest with respect to the authorship and/or publication of this article.

\section{Author Contributions}

S.G. Reed contributed to the conception, data resource acquisition, design, and interpretation, and drafted and critically revised the manuscript; C.S. Miller contributed to the design, data analysis, and interpretation, and drafted and critically revised the manuscript; C.L. Wagner contributed to the study design and interpretation, the data resource design, and data acquisition, and critically revised the manuscript; B.W. Hollis contributed to the data resource design, data acquisition, and study interpretation, and critically reviewed the manuscript; A.B. Lawson contributed to the design, data analysis, and interpretation, and drafted and critically revised the manuscript. All authors gave final approval and agree to be accountable for all aspects of the work.

\section{References}

Bansal AK, Shetty DC, Bindal R, Pathak A. Amelogenin: a novel protein with diverse applications in genetic and molecular profiling. J Oral Maxillofac Pathol. 2012 Sep;16(3):3959.

Bass JK, Chan GM. Calcium nutrition and metabolism during infancy. Nutrition. 2006 Oct; 22(10):1057-66.

Brook AH, Elcock C, Hallonsten AL, Poulson S, Andreasen J, Koch G, et al. The development of a new index to measure enamel defects. In: Brook A, editor. Dental morphology. Sheffield: Sheffield Academic Press; 2001. pp. 5966.

Brooks SP, Gelman A. Alternative methods for monitoring convergence of iterative simulations. J Comput Graph Stat. 1998;7:434-55.

Caufield PW, Li Y, Bromage TG. Hypoplasia-associated severe early childhood caries - a proposed definition. J Dent Res. 2012 Jun;91(6): 544-50.
Chen Y, Lee W, Ferretti GA, Slayton RL, Nelson S. Agreement between photographic and clinical examinations in detecting developmental defects of enamel in infants. J Public Health Dent. 2013;73(3):204-9.

Cianferotti L, Bertoldo F, Bischoff-Ferrari HA, Bruyere O, Cooper C, Cutolo M, et al. Vitamin $\mathrm{D}$ supplementation in the prevention and management of major chronic diseases not related to mineral homeostasis in adults: research for evidence and a scientific statement from the European Society for Clinical and Economic Aspects of Osteoporosis and Osteoarthritis (ESCEO). Endocrine. 2017 May; 56(2):245-61.

Cohen HJ, Diner H. The significance of developmental dental enamel defects in neurological diagnosis. Pediatrics. 1970 Nov;46(5):737-47.

Corrêa-Faria P, Martins-Júnior PA, Vieira-Andrade RG, Oliveira-Ferreira F, Marques LS, Ramos-Jorge ML. Developmental defects of enamel in primary teeth: prevalence and associated factors. Int J Paediatr Dent. 2013 May;23(3):173-9.

Costa FS, Silveira ER, Pinto GS, Nascimento GG, Thomson WM, Demarco FF. Developmental defects of enamel and dental caries in the primary dentition: a systematic review and metaanalysis. J Dent. 2017 May;60:1-7.

Deutsch D, Tam O, Stack MV. Postnatal changes in size, morphology and weight of developing postnatal deciduous anterior teeth. Growth. 1985;49(2):207-17.

Evans KN, Bulmer JN, Kilby MD, Hewison M. Vitamin D and placental-decidual function. J Soc Gynecol Investig. 2004 Jul;11(5):263-71.

FDI Commission on Oral Health Research and Epidemiology. A review of the developmental defects of enamel index (DDE Index). Commission on Oral Health, Research \& Epidemiology. Report of an FDI Working Group. Int Dent J. 1992 Dec;42(6):411-26.
Enamel Hypoplasia and Ca Homeostasis during Pregnancy and at Birth 
Fraser D, Nikiforuk G. The etiology of enamel hypoplasia in children - a unifying concept. J Int Assoc Dent Child. 1982 Jun;13(1):1-11.

Funakoshi Y, Kushida Y, Hieda T. Dental observations of low birth weight infants. Pediatr Dent. 1981 Mar;3(1):21-5.

Giro CM. Enamel hypoplasia in human teeth; an examination of its causes. J Am Dent Assoc. 1947 Mar;34(5):310-7.

Hemmingway A, Kenny LC, Malvisi L, Kiely ME. Exploring the concept of functional vitamin $D$ deficiency in pregnancy: impact of the interaction between 25-hydroxyvitamin D and parathyroid hormone on perinatal outcomes. Am J Clin Nutr. 2018 Oct;108(4):821-9.

Holick MF, Binkley NC, Bischoff-Ferrari HA, Gordon CM, Hanley DA, Heaney RP, et al.; Endocrine Society. Evaluation, treatment, and prevention of vitamin D deficiency: an Endocrine Society clinical practice guideline. J Clin Endocrinol Metab. 2011 Jul;96(7): 1911-30.

Hollis BW. Circulating 25-hydroxyvitamin D levels indicative of vitamin D sufficiency: implications for establishing a new effective dietary intake recommendation for vitamin D. J Nutr. 2005 Feb;135(2):317-22.

Hollis BW, Johnson D, Hulsey TC, Ebeling M, Wagner CL. Vitamin D supplementation during pregnancy: double-blind, randomized clinical trial of safety and effectiveness. J Bone Miner Res. 2011 Oct;26(10):2341-57.

Hollis BW, Kamerud JQ, Selvaag SR, Lorenz JD, Napoli JL. Determination of vitamin D status by radioimmunoassay with an 125I-labeled tracer. Clin Chem. 1993 Mar;39(3):529-33.

Hollis BW, Wagner CL. Assessment of dietary vitamin $\mathrm{D}$ requirements during pregnancy and lactation. Am J Clin Nutr. 2004 May;79(5): $717-26$

Hubbard MJ. Calcium transport across the dental enamel epithelium. Crit Rev Oral Biol Med. 2000;11(4):437-66.

Infante PF, Gillespie GM. Enamel hypoplasia in relation to caries in Guatemalan children. J Dent Res. 1977 May;56(5):493-8.

Jacobsen PE, Haubek D, Henriksen TB, Østergaard JR, Poulsen S. Developmental enamel defects in children born preterm: a systematic review. Eur J Oral Sci. 2014 Feb;122(1):7-14.

Johnsen D, Krejci C, Hack M, Fanaroff A. Distribution of enamel defects and the association with respiratory distress in very low birthweight infants. J Dent Res. 1984 Jan;63(1): 59-64.

Klein H. Etiology of enamel hypoplasia in rickets as determined by studies on rats and swine. J Am Dent Assoc. 1931;18:866-84.

Kovacs CS. Calcium, phosphorus, and bone metabolism in the fetus and newborn. Early Hum Dev. 2015 Nov;91(11):623-8.

Kreshover SJ, Clough OW, Bear DM. A study of prenatal influences on tooth development in humans. J Am Dent Assoc. 1958 Feb;56(2): $230-48$
Kronfeld DS, Ramberg CF Jr, Delivoria-Papadopoulos M. Active transport of calcium across placenta and mammary gland measured in vivo. In: Nichols G, Wasserman RH, editors. Cellular mechanism for calcium transfer and hemeostasis. New York: Academic Press; 1971. p. 339.

Kronfeld R, Schour I. Neonatal dental hypoplasia. J Am Dent Assoc. 1939;26(1):18-31.

Lacruz RS, Habelitz S, Wright JT, Paine ML. Dental enamel formation and implications for oral health and disease. Physiol Rev. 2017 Jul; 97(3):939-93.

Li Y, Navia JM, Bian JY. Prevalence and distribution of developmental enamel defects in primary dentition of Chinese children 3-5 years old. Community Dent Oral Epidemiol. 1995 Apr;23(2):72-9.

Li Y, Navia JM, Caufield PW. Colonization by mutans streptococci in the mouths of 3-and 4 -year-old Chinese children with or without enamel hypoplasia. Arch Oral Biol. 1994 Dec; 39(12):1057-62.

Mellander M, Norén JG, Fredén H, Kjellmer I. Mineralization defects in deciduous teeth of low birthweight infants. Acta Paediatr Scand. 1982 Sep;71(5):727-33.

Merheb R, Arumugam C, Lee W, Collin M, Nguyen C, Groh-Wargo S, et al. Neonatal serum phosphorus levels and enamel defects in very low birth weight infants. JPEN J Parenter Enteral Nutr. 2016 Aug;40(6):835-41.

Miller J, Forrester RM. Neonatal enamel hypoplasia. Br Dent J. 1959;106:93-104.

Nation WA, Matsson L, Peterson JE. Developmental enamel defects of the primary dentition in a group of Californian children. ASDC J Dent Child. 1987 Sep-Oct;54(5):330-4.

Needleman HL, Allred E, Bellinger D, Leviton A, Rabinowitz M, Iverson K. Antecedents and correlates of hypoplastic enamel defects of primary incisors. Pediatr Dent. 1992 MayJun;14(3):158-66.

Needleman HL, Rabinowitz M, Leviton A, Linn S, Schoenbaum S. The relationship between prenatal exposure to lead and congenital anomalies. JAMA. 1984 Jun;251(22):2956-9.

Nelson S, Albert JM, Geng C, Curtan S, Lang K, Miadich S, et al. Increased enamel hypoplasia and very low birthweight infants. J Dent Res. 2013 Sep;92(9):788-94.

Nikiforuk G, Fraser D. Chemical determinants of enamel hypoplasia in children with disorders of calcium and phosphate homeostasis. J Dent Res. 1979 Mar;58(Spec Issue B):1014-5.

Nikiforuk G, Fraser D. The etiology of enamel hypoplasia: a unifying concept. J Pediatr. 1981 Jun;98(6):888-93.

O’Hara RB, Sillanpää MJ. A review of Bayesian variable selection methods: what, how and which. Bayesian Anal. 2009;4(1):85-117.

Papagerakis P, Hotton D, Lezot F, Brookes S, Bonass W, Robinson C, et al. Evidence for regulation of amelogenin gene expression by 1,25-dihydroxyvitamin $\mathrm{D}(3)$ in vivo. J Cell Biochem. 1999 Dec;76(2):194-205.
Pascoe L, Seow WK. Enamel hypoplasia and dental caries in Australian aboriginal children: prevalence and correlation between the two diseases. Pediatr Dent. 1994 May-Jun;16(3): 193-9.

Ranggård L. Dental enamel in relation to ionized calcium and parathyroid hormone. Studies of human primary teeth and rat maxillary incisors. Swed Dent J Suppl. 1994;101:1-50.

Ranggård L, Norén JG, Nelson N. Clinical and histologic appearance in enamel of primary teeth in relation to neonatal blood ionized calcium values. Scand J Dent Res. 1994 Oct; 102(5):254-9.

Ranggård L, Östlund J, Nelson N, Norén JG. Clinical and histologic appearance in enamel of primary teeth from children with neonatal hypocalcemia induced by blood exchange transfusion. Acta Odontol Scand. 1995 Apr; 53(2): 123-8.

Reed SG, Voronca D, Wingate JS, Murali M, Lawson AB, Hulsey TC, et al. Prenatal vitamin D and enamel hypoplasia in human primary maxillary central incisors: a pilot study. Pediatr Dent J. 2017 Apr;27(1):21-8

Richards LF, Westmoreland WW, Tashiro M, Morrison JT. Nonfluoride enamel hypoplasia in varying fluoride-temperature zones. J Am Dent Assoc. 1967 Dec;75(6):1412-8.

Rushton MA. On the fine contour lines of the enamel of milk teeth. Dent Rec. 1933;53. 170-1.

Sabel N, Dietz W, Lundgren T, Nietzsche S, Odelius $\mathrm{H}$, Rythén M, et al. Elemental composition of normal primary tooth enamel analyzed with XRMA and SIMS. Swed Dent J. 2009a;33(2):75-83

Sabel N, Klinberg G, Nietzsche S, Robertson A Odelius H, Norén JG. Analysis of some elements in primary enamel during postnatal mineralization. Swed Dent J. 2009b;33(2):8595.

Salanitri S, Seow WK. Developmental enamel defects in the primary dentition: aetiology and clinical management. Aust Dent J. 2013 Jun; 58(2):133-40; quiz 266.

Sarnat BG, Schour I. Enamel hypoplasia (chronologic enamel aplasia) in relation to systemic disease: a chronologic, morphologic and etiologic classification. J Am Dent Assoc. 1941; 28(12):1989-2000.

Sarnat BG, Schour I. Enamel hypoplasia (chronologic enamel aplasia) in relation to systemic disease: a chronologic, morphologic and etiologic classification. J Am Dent Assoc. 1942; 29(1):67-75.

Sema AP, Canturk N, Dagalp R, Yagan M. Age determination from central incisors of fetuses and infants. Forensic Sci Int. 2009 Jan;184(13): $15-20$.

Seow WK. Enamel hypoplasia in the primary dentition: a review. ASDC J Dent Child. 1991 Nov-Dec;58(6):441-52. 
Seow WK, Leishman SJ, Palmer JE, Walsh LJ, Pukallus M, Barnett AG. A longitudinal observational study of developmental defects of enamel from birth to 6 years of age. JDR Clin Trans Res. 2016 Oct;1(3):285-91.

Seow WK, Romaniuk K, Sclavos S. Micromorphologic features of dentin in vitamin D-resistant rickets: correlation with clinical grading of severity. Pediatr Dent. 1989 Sep;11(3): 203-8.

Spiegelhalter DJ, Best NG, Carlin BP, van der Linde A. The deviance information criterion: 12 years on. J R Stat Soc Series B Stat Methodol. 2014;76(3):485-93.

Steichen JJ, Gratton TL, Tsang RC. Osteopenia of prematurity: the cause and possible treatment. J Pediatr. 1980 Mar;96(3 Pt 2):528-34.
Stukes TM, Shary JR, Wei W, Ebeling MD, Dezsi KB, Shary FS, et al. Circulating cathelicidin concentrations in a cohort of healthy children: influence of age, body composition, gender and vitamin D status. PLoS One. 2016 May;11(5):e0152711.

Sweeney EA, Cabrera J, Urrutia J, Mata L. Factors associated with linear hypoplasia of human deciduous incisors. J Dent Res. 1969 NovDec;48(6):1275-9.

Taji SS, Seow WK, Townsend GC, Holcombe T. Enamel hypoplasia in the primary dentition of monozygotic and dizygotic twins compared with singleton controls. Int J Paediatr Dent. 2011 May;21(3):175-84.

Via WF Jr, Churchill JA. Relationship of enamel hypoplasia to abnormal events of gestation and birth. J Am Dent Assoc. 1959 Oct;59(4): 702-7.
Via WF Jr, Churchill JA. Relationships of cerebral disorder to faults in dental enamel. AMA J Dis Child. 1957 Aug;94(2):137-42.

Via WF Jr, Elwood WK, Bebin J. The effect of maternal hypoxia upon fetal dental enamel. Henry Ford Hosp Med Bull. 1959 Jun;7(2):94101.

Wagner CL, McNeil RB, Johnson DD, Hulsey TC, Ebeling M, Robinson C, et al. Health characteristics and outcomes of two randomized vitamin D supplementation trials during pregnancy: a combined analysis. J Steroid Biochem Mol Biol. 2013 Jul;136:313-20.

Wöltgens JH, Lyaruu DM, Bronckers AL, Bervoets TJ, Van Duin M. Biomineralization during early stages of the developing tooth in vitro with special reference to secretory stage of amelogenesis. Int J Dev Biol. 1995 Feb; 39(1):203-12. 